\title{
Clinical, Radiographic, Biochemical and Histological Findings of Florid Cemento-Osseous Dysplasia and Report of a Case
}

\author{
Marcelo GONÇALVES ${ }^{1}$ \\ Ronaldo PÍSPICO ${ }^{2}$ \\ Fábio de Abreu ALVES ${ }^{3}$ \\ Carlos Eduardo B. LUGÃO ${ }^{1}$ \\ Andréa GONÇALVES ${ }^{1}$ \\ ${ }^{1}$ Department of Diagnosis and Surgery, Faculty of Dentistry of Araraquara, \\ São Paulo State University (UNESP), Araraquara, SP, Brazil \\ ${ }^{2}$ Department of Oral Emergency, Faculty of Dentistry, University of Santo Amaro (UNISA), São Paulo, SP, Brazil \\ ${ }^{3}$ Department of Oral Pathology, Faculty of Dentistry of Piracicaba, \\ State University of Campinas (UNICAMP), Piracicaba, SP, Brazil
}

\begin{abstract}
Florid cemento-osseous dysplasia has been described as a condition that characteristically affects the jaws of middle-aged black women. It usually manifests as multiple radiopaque cementum-like masses distributed throughout the jaws. This condition has also been classified as gigantiform cementoma, chronic sclerosing osteomyelitis, sclerosing osteitis, multiple estenosis and sclerotic cemental masses. The authors present a case of an uncomplicated florid cemento-osseous dysplasia in a 48-year-old black woman. Multiple sclerotic masses with radiolucent border in the mandible were identified radiographically. Histopathologic findings revealed formation of calcified dense sclerotic masses similar to cementum. All clinical, radiographic, biochemical and histological features were suggestive of the diagnosis of florid cemento-osseous dysplasia.
\end{abstract}

Key Words: florid cemento-osseous dysplasia, florid osseous dysplasia, fibro-osseous lesions.

\section{INTRODUCTION}

The classification of cemento-osseous lesions of the jaws has long been a matter of discussion for pathologists and clinicians. A review of the literature shows a wide range of terminology used by authors to describe what seem to be similar lesions (1-3). The current classification of cementomatous lesions, released in 1992 by the World Health Organization (4), is based on age, sex and histopathologic, radiographic and clinical characteristics, as well as location of the lesion. This classification includes cemento-ossifying fibroma, benign cementoblastoma and the cemento-osseous dysplasia group, in which periapical cemental dysplasia and florid cemento-osseous dysplasia are included.

Florid cemento-osseous dysplasia is more commonly seen in middle-aged black women, although it also may occur in Caucasians and Asians (5,6). In some cases, a familial trend can be observed (7-10). The process may be totally asymptomatic and, in such cases, the lesion is detected when radiographs are taken for some other purposes (11). Symptoms such as dull pain or drainage are almost always associated with exposure of sclerotic calcified masses in the oral cavity. This may occur as the result of progressive alveolar atrophy under a denture or after extraction of teeth in the affected area $(6,12)$.

Radiographically, the lesions appear as multiple sclerotic masses, located in two or more quadrants, usually in the tooth-bearing regions. They are often confined within the alveolar bone (13). Histologically, these lesions are composed of anastomosing bone trabeculae and layers of cementum-like calcifications embedded in a fibroblastic background $(3,6)$. 
Management of these conditions involves clinicalradiographic follow-up. Endodontic therapy should not be done before a definitive diagnosis is obtained, especially when it is based solely on radiographic findings and no other signs and syntoms are present (14).

This paper describes the case of a patient who was diagnosed with florid cemento-osseous dysplasia on the basis of clinical, radiographic, biochemical and histological findings.

\section{CASE REPORT}

A 48-year-old black female presented for routine dental care. She was systemically healthy and extra-oral examination was within normal limits. Intraoral

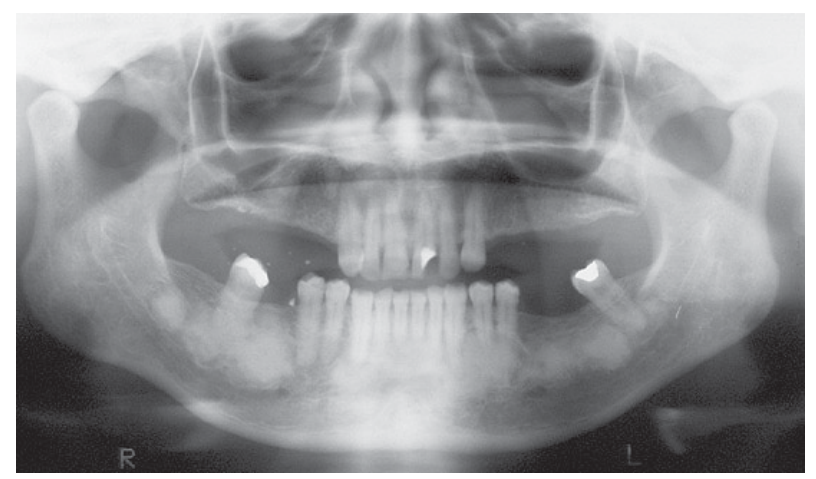

Figure 1. Panoramic radiograph showing multiple radiopaque lesions in the periapical region of the mandible. Note that the epicenter of the lesions is above the inferior alveolar canal.

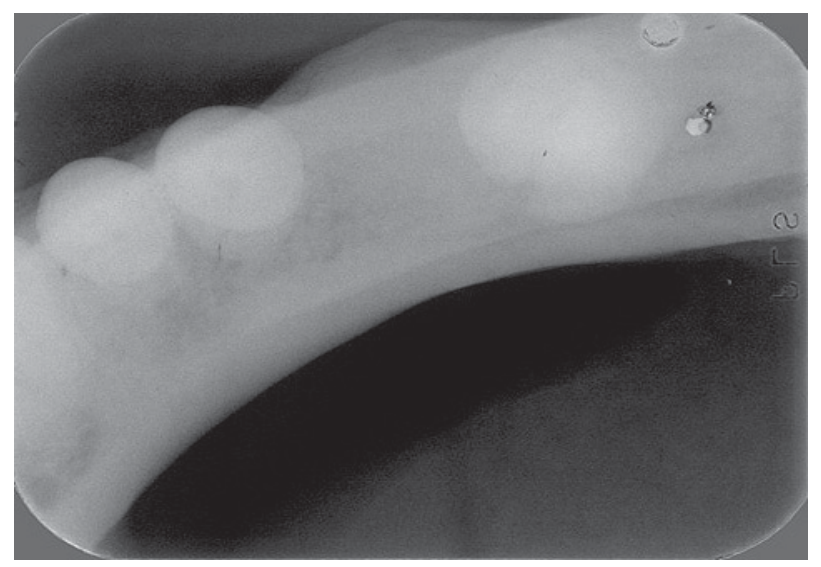

Figure 3. Occlusal radiograph showing slight buccal expansion at the molar region in the right side of the mandible. examination revealed a partially edentulous area and the overlying gengiva and mucosa were normal without any clinical signs of inflammation.

Panoramic, periapical and oclusal radiographs were obtained. Multiple sclerotic masses with radiolucent borders were found in the mandible, confined within the alveolus at a level corresponding to the roots of the teeth, above the inferior alveolar canal (Fig. 1). The periapical radiographs showed absence of lamina dura surrounding the apical region of affected teeth (Fig. 2). The occlusal images revealed slight buccal expansion at the molar region on the right side of the mandible (Fig. 3). Biopsy of this lesion showed formations of dense sclerotic calcified cementum-like masses. The periphery of the lesion showed globular or ovoid structures of cementoid appearance involved by thin fibrous tissue (Fig. 4).

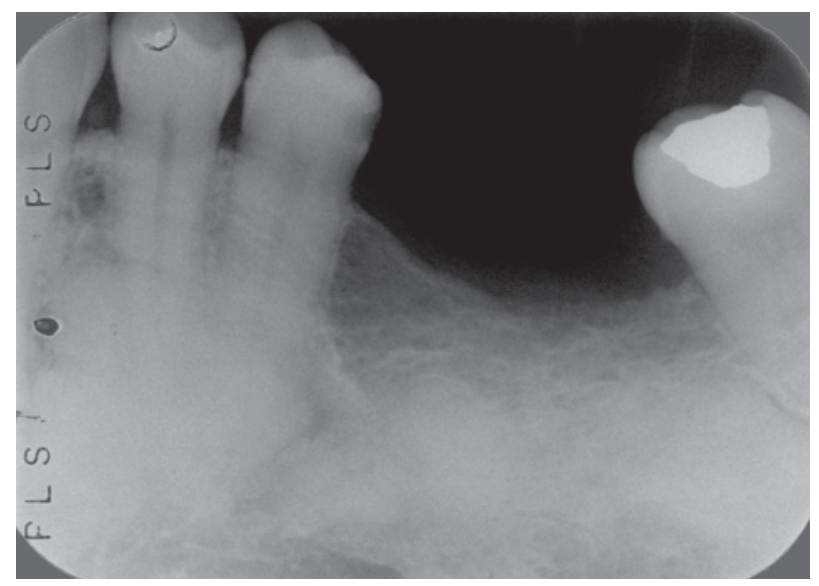

Figure 2. Periapical radiographic image showing the absence of lamina dura surrounding the apical region of affected teeth.

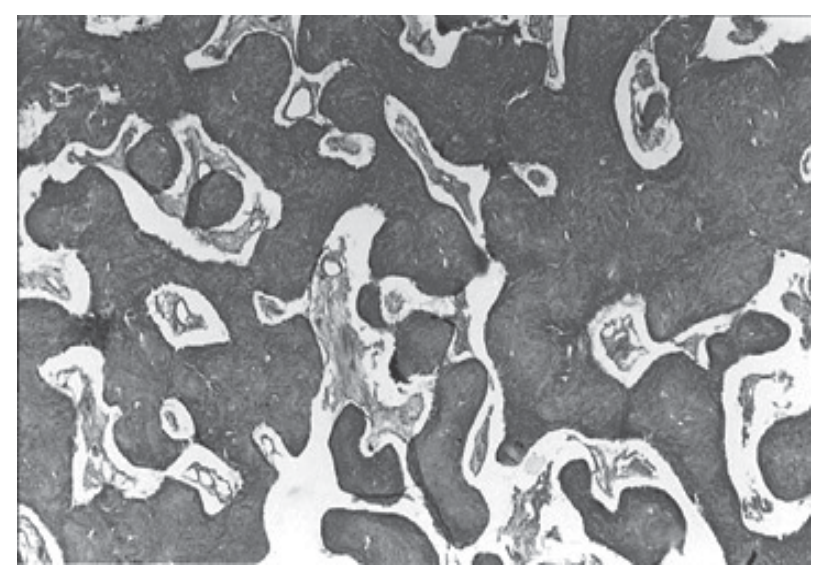

Figure 4. Histologic findings revealing the formation of calcified dense sclerotic cementum-like masses. 
Biochemical analysis of serum alkaline phosphatase, calcium and phosphorus were carried out for differential diagnosis with Paget's disease and were shown to be within the normal limits.

\section{DISCUSSION}

Florid cemento-osseous dysplasia was first described by Melrose et al. in 1976 (2). This condition has been interpreted as a dysplastic lesion or developmental anomaly arising in tooth-bearing areas. These lesions exhibit a sclerotic appearance similar to that of other lesions on conventional radiographs. Paget's disease of the bone may have a cotton-wool appearance. However, this condition affects the bone of the entire mandible and shows loss of lamina dura, whereas florid cementoosseous dysplasia is centered above the inferior alveolar canal and its cervical two thirds are normal (15). Paget's disease is often polyostotic, involving other bones such as spine, femur, skull, pelvis and sternum (16) and produces biochemical serum changes, such as elevated alkaline phosphate levels $(17,18)$. No biochemical alterations and others bone involvement were found in the case reported.

Another disease that may resemble the florid cemento-osseous dysplasia is chronic diffuse sclerosing osteomyelitis. It appears as a single, poorly delineated opaque segment of the mandible, whereas florid cementoosseous dysplasia is seen as multiple round or lobulated opaque masses. Chronic diffuse sclerosing osteomyelitis involves the body of the mandible from the alveolus to the inferior border and may extend into the ramus. In addition, florid cemento-osseous dysplasia is frequently associated to black women, while chronic diffuse sclerosing osteomyelitis is seen predominantly in adult Caucasian men $(19,20)$.

Florid cemento-osseous dysplasia may be familial with an autosomal dominant inheritance pattern, but there are only a few examples in the literature in which the familial pattern has been confirmed $(1,8,10)$. In the present case no familial aspects of the disease could be established.

Regarding the treatment of florid cemento-osseous dysplasia, complete resection of the lesion would be impractical because it usually occupies most of the mandible and maxilla. When surgical intervention is indicated, a remodeling resection is recommended for esthetic reasons (6).

\section{RESUMO}

A displasia cemento-óssea florida tem sido descrita como uma condição que afeta tipicamente os maxilares de mulheres negras de meia idade. Ela geralmente se manifesta como múltiplas massas radiopacas semelhantes ao cemento distribuídas nos maxilares. Esta condição também tem sido classificada por vários autores como cementoma gigantiforme, osteomielite esclerosante crônica, osteíte esclerosante e massas de cemento escleróticas. Os autores apresentam um caso de displasia cemento-óssea florida não complicada em uma mulher negra de 48 anos de idade. Múltiplas massas escleróticas com bordas radiolúcidas na mandíbula foram identificadas radiograficamente. Os achados histopatológicos revelaram formação de massas escleróticas densas calcificadas semelhantes ao cemento. Todos os aspectos clínicos, radiográficos, bioquímicos e histológicos foram sugestivos do diagnóstico de displasia cemento-óssea florida.

\section{REFERENCES}

1. Young SK, Markowitz NR, Sullivan S, Seale TW, Hirschi R. Familial gigantiform cementoma: classification and presentation of a large pedigree. Oral Surg Oral Med Oral Pathol 1989;68:740-747.

2. Melrose RJ, Abrams AM, Mills BG. Florid osseous dysplasia. A clinical-pathologic study of thirty-four cases. Oral Surg Oral Med Oral Pathol 1976;41:62-82.

3. Waldron CA, Giansanti JS, Browand BC. Sclerotic cemental masses of the jaws (so-called chronic sclerosing osteomyelitis, sclerosing osteitis, multiple enostosis, and Gigantiform cementoma). Oral Surg Oral Med Oral Pathol 1975;39:590604.

4. Kramer IRH, Pindborg JJ, Shear M. Neoplasma and others lesions related to bone. In: World Health Organization (Editors) - Histologic Typing of Odontogenic Tumours. Berlim: Springer-Verlag; 1992. p. 28-31.

5. Miyake M, Nagahata S. Florid cemento-osseous dysplasia. Report of a case. Int J Oral Maxillofac Surg 1999;28:56-57.

6. Waldron CA. Fibro-osseous lesions of the jaws. J Oral Maxillofac Surg 1985;43:249-262.

7. Cannon JS, Keller EE, Dahlin DC. Gigantiform cementoma. Report of two cases (mother and son). J Oral Surg 1980;38:6570 .

8. Oikarinen K, Altonen M, Happonen RP. Gigantiform cementoma affecting a Caucasian family. Br J Oral Maxillofac Surg 1991;29:194-197.

9. Coleman H, Altini M, Kieser J, Nissenbaum M. Familial florid cemento-osseous dysplasia - a case report and review of the literature. J Dent Assoc S Afr 1996;51:766-770.

10. Toffanin A, Benetti R, Manconi R. Familial florid cementoosseous dysplasia: a case report. J Oral Maxillofac Surg 2000;58:1440-1446.

11. Gariba-Silva, R, Souza-Neto MD, Carvalho Jr JR, Saquy PC, Pecora JD. Periapical cemental dysplasia: case report. Braz Dent J 1999;10:55-57.

12. Said-al-Naief NA, Surwillo E. Florid osseous dysplasia of the mandible: report of a case. Compend Contin Educ Dent 1999;20:1017-1019.

13. Damm DD, Fantasia JE. Multifocal mixed radiolucencies. Florid cemento-osseous dysplasia. Gen Dent 2001;49:461538. 
14. Smith S, Patel K, Hoskinson AE. Periapical cemental dysplasia: a case of misdiagnosis. Br Dent J 1998;185:122123.

15. Langlais RP, Langland OE, Nortjé CJ. Diagnostic Imaging of the Jaws. 1st ed. Malvern: Williams \& Wilkins; 1995.

16. White SC, Pharoah MJ. Oral Radiology - Principles and Interpretation. 4th ed. Saint Louis: Mosby; 2000.

17. Wolf J, Heitamen J, Sane J. Florid cemento-osseous dysplasia (gigantiform cementoma) in a Caucasian woman. Br J Oral
Maxillofac Surg 1989;27:46-52.

18. Loh FC, Yeo JF. Florid cemento-osseous dysplasia in Orientals. Oral Surg Oral Med Oral Pathol 1989;68:748-753.

19. Schneider LC, Mesa ML. Differences between florid osseous dysplasia and chronic diffuse sclerosing osteomyelitis. Oral Surg Oral Med Oral Pathol 1990;70:308-312.

20. Groot RH, van Merkesteyn JP, Bras J. Diffuse sclerosing osteomyelitis and florid osseous dysplasia. Oral Surg Oral Med Oral Pathol Oral Radiol Endod 1996;81:333-342.

Accepted September 3, 2003 